\title{
Ferroelastic Fingerprints in Methylammonium Lead lodide Perovskite
}

Ilka M. Hermes, Simon A. Bretschneider, Victor W. Bergmann, Dan Li, Alexander

Klasen , Julian Mars, Wolfgang Tremel, Frédéric Laquai, Hans-Jürgen Butt,

Markus Mezger, Rüdiger Berger, Brian J. Rodriguez, and Stefan A. L. Weber

J. Phys. Chem. C, Just Accepted Manuscript • DOI: 10.1021/acs.jpcc.5b11469 • Publication Date (Web): 12 Feb 2016

Downloaded from http://pubs.acs.org on February 16, 2016

\section{Just Accepted}

"Just Accepted" manuscripts have been peer-reviewed and accepted for publication. They are posted online prior to technical editing, formatting for publication and author proofing. The American Chemical Society provides "Just Accepted" as a free service to the research community to expedite the dissemination of scientific material as soon as possible after acceptance. "Just Accepted" manuscripts appear in full in PDF format accompanied by an HTML abstract. "Just Accepted" manuscripts have been fully peer reviewed, but should not be considered the official version of record. They are accessible to all readers and citable by the Digital Object Identifier (DOI@). "Just Accepted" is an optional service offered to authors. Therefore, the "Just Accepted" Web site may not include all articles that will be published in the journal. After a manuscript is technically edited and formatted, it will be removed from the "Just Accepted" Web site and published as an ASAP article. Note that technical editing may introduce minor changes to the manuscript text and/or graphics which could affect content, and all legal disclaimers and ethical guidelines that apply to the journal pertain. ACS cannot be held responsible for errors or consequences arising from the use of information contained in these "Just Accepted" manuscripts. 


\title{
Ferroelastic Fingerprints in Methylammonium Lead Iodide Perovskite
}

\author{
Ilka M. Hermes, ${ }^{\dagger}$ Simon A. Bretschneider, ${ }^{\dagger}$ Victor W. Bergmann,,$^{\dagger}$ Dan Li, ${ }^{\dagger}$ Alexander Klasen, ${ }^{\dot{t}}$ \\ Julian Mars, ${ }^{\dagger}$ Wolfgang Tremel, ${ }^{*}$ Frédéric Laquai, ${ }^{\dagger}{ }^{\S}$ Hans-Jürgen Butt, ${ }^{\dagger}$ Markus Mezger, ${ }^{\dagger}, \|$ \\ Rüdiger Berger, ${ }^{\dagger}$ Brian J. Rodriguez, ${ }^{\perp}$ and Stefan A. L. Weber ${ }^{\dagger} \|, * *$ \\ ${ }^{\dagger}$ Max Planck Institute for Polymer Research, Ackermannweg 10, 55128 Mainz, Germany

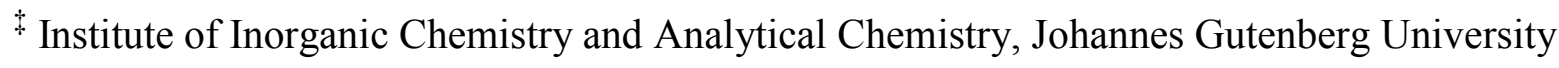 \\ Mainz, Duesbergweg 10-14, 55128 Mainz, Germany \\ $\S$ Solar and Photovoltaics Engineering Research Center (SPERC), King Abdullah University of \\ Science and Technology (KAUST), Thuwal, Kingdom of Saudi Arabia \\ "Institute of Physics, Johannes Gutenberg University Mainz, Duesbergweg 10-14, 55128 Mainz, \\ Germany \\ ${ }^{\perp}$ School of Physics and Conway Institute of Biomolecular and Biomedical Research, University \\ College Dublin, Belfield, Dublin 4, Ireland
}




\begin{abstract}
KEYWORDS
Perovskite solar cells, hybrid perovskites, piezoresponse force microscopy, ferroelasticity, ferroelectricity, twin domains
\end{abstract}

\begin{abstract}
Methylammonium lead iodide $\left(\mathrm{MAPbI}_{3}\right)$ perovskite shows an outstanding performance in photovoltaic devices. However, certain material properties, especially the possible ferroic behavior, remain unclear. We observed distinct nanoscale periodic domains in the piezoresponse of $\mathrm{MAPbI}_{3}(\mathrm{Cl})$ grains. The structure and the orientation of these striped domains indicate ferroelasticity as their origin. By correlating vertical and lateral piezoresponse force microscopy experiments performed at different sample orientations with x-ray diffraction, the preferred domain orientation was suggested to be the $a_{1}$-a $a_{2}$-phase. The observation of these ferroelastic fingerprints appears to strongly depend on the film texture and thus the preparation route. The formation of the ferroelastic twin domains could be induced by internal strain during the cubictetragonal phase transition.
\end{abstract}

\title{
INTRODUCTION
}

The development of solar cells based on methylammonium lead iodide $\left(\mathrm{MAPbI}_{3}\right)$ perovskite has seen impressive dynamics over the past few years. ${ }^{1-3}$ Intensive research has pushed the power conversion efficiency (PCE) of perovskite solar cells to a certified value of over $20 \%$. ${ }^{4}$ Besides their inexpensive production, the success of perovskite solar cells originates from the unique properties of the perovskite: a strong optical absorption and charge carrier diffusion lengths of up to $1 \mu \mathrm{m}$ that lead to internal quantum efficiencies of more than $90 \% .^{5-11}$ However, the physical 
origin of these properties as well as their dependence on the device architecture and on the preparation route are not fully understood.

A fundamental material property that has been suggested in the context of the unique solar cell performance is ferroelectricity. ${ }^{12}$ Frost et al. suggested that charged ferroelectric domain walls could act as charge carrier-specific pathways through the perovskite grains. ${ }^{12}$ It has also been proposed that ferroelectricity of the perovskite material causes the hysteretic anomaly that has been observed in the photocurrent- voltage $(I-V)$ curves of perovskite solar cells. ${ }^{12-17}$ This hysteresis leads to an overestimation of the PCE and its origin is heavily discussed. It has been suggested that time dependent processes, such as migrating ions, electronic traps or the alignment of the spontaneous polarization upon applying an electric field, contribute to the hysteresis. ${ }^{5-6,13,18-24}$ However, more recent publications indicate that ferroelectricity does not contribute to the hysteresis at all or only in a minor way, as opposed to ion migration and electronic traps. ${ }^{18,20,23,25}$

$\mathrm{MAPbI}_{3}$, like other perovskite materials, fulfils the structural requirements for a ferroic material: The lead and the halide ions build a three dimensional network of corner-sharing $\mathrm{PbI}_{6}$ octahedra. The organic methylammonium cations $\left(\mathrm{MA}^{+}\right)$occupy the cuboctahedral gap. At temperatures above $327 \mathrm{~K}, \mathrm{MAPbI}_{3}$ crystallizes in a cubic structure, between $165 \mathrm{~K}$ and $327 \mathrm{~K}$ in a tetragonal structure and below $165 \mathrm{~K}$ in an orthorhombic structure. ${ }^{26-29}$ The tetragonal structure at room temperature was found to crystallize either the non-polar, centrosymmetric space group $I 4 / \mathrm{mcm}^{28,30-31}$ or the polar space group $I 4 \mathrm{~cm}^{26-27}$ The symmetry lowering phase transition from the cubic $P m \overline{3} m^{32}$ to the non-centrosymmetric tetragonal $I 4 c m$ structure in $\mathrm{MAPbI}_{3}$ classifies as ferroelectric, as well as ferroelastic. ${ }^{33}$ 
A ferroelastic phase transition leads to a distortion of the crystal lattice causing a spontaneous strain in the material - analog to the spontaneous polarization/magnetization in ferroelectric/ferromagnetic materials. Upon application of an external stress, this spontaneous strain can switch its direction in the crystal lattice. ${ }^{34}$ Thereby, the internal strain can be lowered by the formation of twin domains, that are oriented along different crystalline axes. A tetragonal structure allows spontaneous strain orientations along the $a_{1}, a_{2}$ and $c$ axes. ${ }^{33}$ Like ferroelectricity, ferroelasticity is a nonlinear property and commonly observed in materials with a perovskite crystal structure. ${ }^{33-34}$

To shed light on the microscopic origin of these effects, atomic force microscopy (AFM) can correlate the topography of a sample to other local material properties, such as electrical potential, piezoelectricity or conductivity. ${ }^{22,35-37}$ In particular, piezoresponse force microscopy (PFM) can locally probe the electromechanical properties of piezoelectric samples. It is an AFM method based on the inverse piezoelectric effect. As ferroelectricity is always coupled to piezoelectricity, PFM can also visualize ferroic domains. ${ }^{36-37}$ By scanning a surface in contact mode and simultaneously applying an AC voltage via a conductive cantilever, a piezoelectric material deforms periodically. The amplitude of the piezoresponse gives the magnitude of the electromechanical coupling and thus the positions of domain walls, where the material's piezoresponse is minimal. The phase between excitation and piezoresponse contains information about the orientation of the domains. Two measurement modes are possible: (a) vertical PFM uses the cantilever vertical cantilever deflection signal to detect the out-of-plane piezoresponse and (b) lateral PFM uses the lateral deflection signal caused by torsion of the cantilever to detect in-plane piezoresponse. The polarization direction of ferroelectric domains can be permanently 
switched by applying a DC bias during a scan in contact mode. ${ }^{36-37}$ Furthermore, PFM can locally measure ferroelectric hysteresis loops.

Several groups have performed PFM measurements on $\mathrm{MAPbI}_{3}$ perovskite films. Yet, the findings of these studies were contradictory. Kutes et al. observed switchable ferroelectric domains in their $\mathrm{MAPbI}_{3}$ films ${ }^{38}$ which was confirmed by subsequent PFM studies. ${ }^{16,39-41}$ However, Xiao et al. reported that they did not find any evidence of ferroelectricity using PFM. ${ }^{19}$ Recently, two publications claimed that the $\mathrm{MAPbI}_{3}$ perovskite does not exhibit ferroelectricity at room temperature based on PFM measurements and macroscopic polarization methods. ${ }^{42-43}$ The previous PFM studies prepared the perovskite films by various preparation routines and obtained dense perovskite films with grain sizes up to $1 \mu \mathrm{m}$.

Here, we prepared $\mathrm{MAPbI}_{3}(\mathrm{Cl})$ films via solvent annealing, yielding in less dense films with grains up to $10 \mu \mathrm{m}$ that exhibited a high crystalline orientation and a distinct morphology of multiple terraces. On top of these grains, we performed vertical and lateral PFM and locally resolved an at least partially in-plane striped structure with spacing between $100 \mathrm{~nm}$ and $350 \mathrm{~nm}$ in the PFM signal that could not be observed in their topography. By correlating vertical and lateral PFM with x-ray diffraction experiments, we concluded that the $a_{1}$ - $a_{2}$-phase is the preferred crystal orientation in these domains. The structure and the orientation of the domains suggest that $\mathrm{MAPbI}_{3}$ is ferroelastic, causing the twin domain pattern when prepared as described.

\section{EXPERIMENTAL SECTION}

Sample preparation. Methylammonium iodide $\left(\mathrm{CH}_{3} \mathrm{NH}_{3} \mathrm{I}\right)$ was synthesized as described by Lee et $a l .^{3}$ Lead chloride $\left(\mathrm{PbCl}_{2}\right.$, Sigma Aldrich, 99.999\%) was dehydrated under high vacuum conditions and in nitrogen atmosphere at $60{ }^{\circ} \mathrm{C}$. The perovskite solution was prepared in a 3:1 
molar ratio of the precursors $\mathrm{CH}_{3} \mathrm{NH}_{3} \mathrm{I}$ and $\mathrm{PbCl}_{2}$ with a concentration of $40 \mathrm{wt} \%$ in anhydrous dimethylformamide (DMF, Sigma).

Indium tin oxide (ITO) substrates (PGO, $R_{\square} \leq 20 \frac{\Omega}{\square}$ ) were cleaned with $2 \%$ Hellmanex II, acetone and isopropanol and treated with an argon plasma for $20 \mathrm{~min}$ prior to the deposition of filtered (450 nm) poly(3,4-ethylenedioxythiophene) polystyrene sulfonate (PEDOT:PSS, Heraeus Clevios ${ }^{\mathrm{TM}}$ P VPAI 4083) in water. The PEDOT:PSS/water mixture was deposited on the substrate by spin-coating at 2500rpm for $5 \mathrm{~s}$, followed by $5000 \mathrm{rpm}$ for $25 \mathrm{~s}$ and subsequently annealed at $140{ }^{\circ} \mathrm{C}$ for $20 \mathrm{~min}$. The samples were transferred into a nitrogen-filled glovebox with less than 1 ppm $\mathrm{H}_{2} \mathrm{O}$. The perovskite solution was kept at $60{ }^{\circ} \mathrm{C}$ prior deposition. For a 1 by 1 inch sample, around $100 \mu \mathrm{L}$ of solution were used and spin-coated for $45 \mathrm{~s}$ at $2000 \mathrm{rpm}$. The samples then rested at least 30 minutes in the glovebox. For the solvent annealing, the samples were placed on the hotplate, $10 \mu \mathrm{L}$ of DMF were dropped on the hotplate, similar to Xiao et al. ${ }^{44}$ The substrates and the DMF were covered with a watch glass in a way that the DMF could dissipate during the solvent-annealing. The substrates were annealed for $1 \mathrm{~h}$ at $100{ }^{\circ} \mathrm{C}$ in the presence of DMF and in a second annealing step in nitrogen atmosphere for another hour at $100{ }^{\circ} \mathrm{C}$. The cells were kept at least 12 hours in the glovebox prior to measurements.

Piezoresponse force microscopy. Piezoresponse characterization of the perovskite films was performed on an MFP-3D atomic force microscope from Asylum Research (Oxford Instruments) and an HF2 Lock-in amplifier by Zürich Instruments. To avoid degradation of the hygroscopic perovskite material by humidity, the MFP-3D was operated in a glovebox in nitrogen atmosphere. Following the preparation, the samples were quickly transferred from the preparation glovebox into the MFP-3D glovebox. The PFM measurements were performed at room temperature with PPP-EFM cantilevers from Nanosensors with free resonance frequencies 
of $70 \mathrm{kHz}$ and spring constants of $k \sim 2 \mathrm{~N} / \mathrm{m}$. AC voltages with peak-amplitudes between 1 and 2.5 V were applied to the conductive cantilevers to excite the material. We chose AC frequencies of around $300 \mathrm{kHz}$, just below the contact resonance to make use of the resonance enhancement. No additional back electrode was used, a small area of the perovskite was removed by scratching and PEDOT:PSS was connected to ground.

For switching experiments the sample was scanned in contact mode at scan speeds below $0.5 \mathrm{~Hz}$, while simultaneously applying a DC voltage of up to $4 \mathrm{~V}$ via the conductive cantilever.

Lateral PFM was performed at a drive frequency of $600 \mathrm{kHz}$. We used an AC amplitude of 2.5 V.

X-ray diffraction. X-ray diffraction of the perovskite film was measured using $\mathrm{Cu} \mathrm{K} \alpha$ radiation (Rigaku MicroMax 007 x-ray generator, Osmic Confocal Max-Flux curved multilayer optics). The sample was mounted in reflection geometry at an incident angle of $4.5^{\circ}$ on a 6-circle diffractometer. 2D diffraction patterns were recorded by an image plate detector (Mar345, 150 $\mu \mathrm{m}$ pixel size) at a sample-detector distance of $356.83 \mathrm{~mm}$.

UV-vis absorption. The absorption spectrum of the $\mathrm{MAPbI}_{3}$ film was measured with a Perkin Elmer Lambda 900 spectrometer with integrated sphere.

\section{RESULTS AND DISCUSSION}

The topography of the solvent annealed $\mathrm{MAPbI}_{3}$ film showed grains in varying shapes and sizes that ranged between $1 \mu \mathrm{m}$ and $10 \mu \mathrm{m}$ in diameter (Figure 1 (a)). The surface of these grains exhibited a distinct terrace structure suggesting a high crystallinity of the $\mathrm{MAPbI}_{3}$ compound. While on top of the terraces no extraordinary topographic features were observed, the vertical PFM phase (Figure 1 (b)) and amplitude (Figure 1 (c)) revealed a striped structure with a spacing 
of $100 \mathrm{~nm}$ up to $350 \mathrm{~nm}$. In the PFM phase (Figure 1 (b)), only a weak contrast between adjacent stripes was observed. For adjacent out-of-plane ferroelectric domains a phase difference of $180^{\circ}$ would be expected. However, the phase difference of only a few degrees in Figure 1 (b) indicates that the domains might be oriented partially in-plane. The piezoresponse amplitude (Figure 1 (c)) showed the same structure as the PFM phase with a strong contrast, e.g. in the magnified areas 1 and 2.

Materials with a center of inversion do not exhibit piezoelectricity. ${ }^{45}$ Therefore, the presence of a piezoresponse on the perovskite grains suggests that the material does not crystallize in the centrosymmetric space group $I 4 / \mathrm{mcm}^{28,30-31}$ but more likely in the polar space group $I 4 \mathrm{~cm}$. The piezoresponse increased linearly with the applied electric potential up to $V_{A C}=2.5 \mathrm{~V}$ (Supporting Information Figure S1).

Within single grains, distances between adjacent stripes are largely uniform. On different grains, however, the spacing varies between $100 \mathrm{~nm}$ and $350 \mathrm{~nm}$. The amplitude profiles in Figure 1 (d) were extracted along the red and the blue line in area 1 and area 2 in Figure 1 (c), respectively. While stripes of the same contrast on the grain in the magnified area 1 were on average $230 \mathrm{~nm}$ apart, stripes of the same contrast on the grain in area 2 had distances of only $120 \mathrm{~nm}$. It appeared that the spacing between the grains was correlated with the grain size, as it would be expected for ferroelastic domains. ${ }^{46}$ However, due to the complex morphology of the perovskite grains, single grains could not be readily distinguished. A statistical analysis of this correlation was therefore not possible. Furthermore, both magnified areas showed that the stripes change their direction by $90^{\circ}$ within a single grain. The $90^{\circ}$ angle between the domains is in good agreement with the tetragonal crystal structure of $\mathrm{MAPbI}_{3}$ at room temperature. ${ }^{26-29} \mathrm{In}$ area 1 the dark stripes became narrower towards stripes with a perpendicular orientation, like needles. 
The periodic structure, the $90^{\circ}$ direction change and the correlation between domain size and grain size is reminiscent of the periodic ferroelastic domains in thin films of the ferroelectric and -elastic ceramics $\mathrm{Pb}_{0.7} \mathrm{Zr}_{0.3} \mathrm{TiO}_{3}(\mathrm{PZT})$ and $\mathrm{Pb}_{\mathrm{x}} \mathrm{Sr}_{1-\mathrm{x}} \mathrm{TiO}_{3}(\mathrm{PST})$, observed by Ivry et al. as well as Matzen et al., respectively. ${ }^{47-48}$ Ferroelastic materials that grow under external stress can reduce this stress by forming twin domains. The external stress can be caused, for example, by epitaxial growth on a substrate that forces the compound into a structure it usually does not crystallize in. As the substrate in our perovskite samples is PEDOT:PSS, an amorphous polymer mixture, epitaxial strain seems unlikely. To exclude a further influence of the substrate we additionally prepared perovskite films directly on ITO glass and observed the same periodic pattern as on PEDOT:PSS (Supporting Information Figure S2).

The preparation of the $\mathrm{MAPbI}_{3}$ films was performed at $100{ }^{\circ} \mathrm{C}$, where the compound crystallizes in a cubic structure. During cooling of the sample, a possibly ferroic phase transition to the tetragonal crystal structure occurs at around $54{ }^{\circ} \mathrm{C} .{ }^{26-29} \mathrm{We}$ propose that this phase transition induces an internal strain that is compensated by the formation of twin domains due to a ferroelasticity of the compound. 

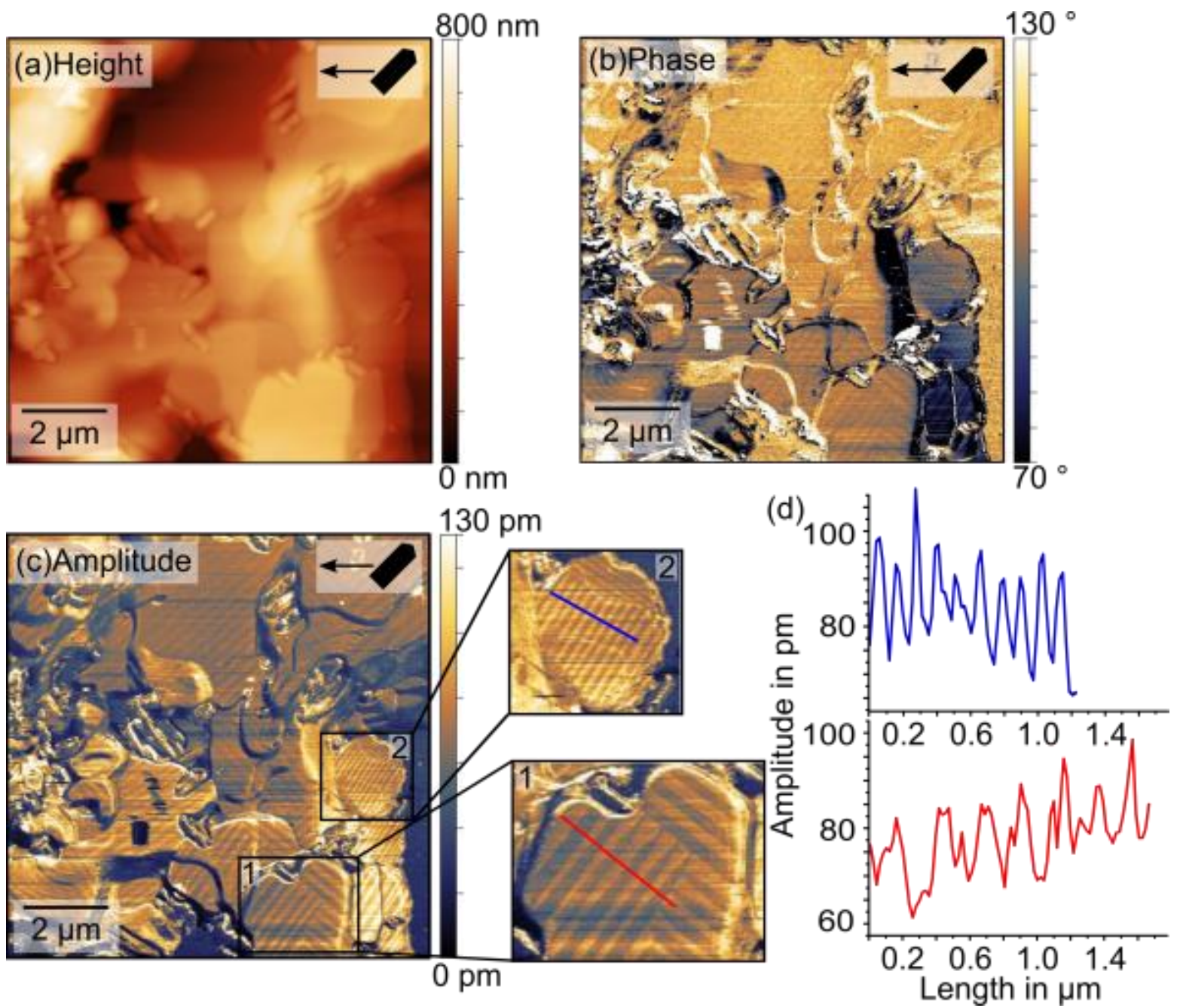

Figure 1. Vertical PFM measurement on $\mathrm{MAPbI}_{3}$ film (a) Topography, (b) PFM phase, (c) PFM amplitude with magnified areas 1 and 2, (d) amplitude profiles extracted along the red line in area 1 (red) and the blue line in area 2 (blue). $\left(V_{A C}=2.5 \mathrm{~V} ; f_{\text {Drive }}=300 \mathrm{kHz}\right.$, scan angle $=45^{\circ}$, cantilever orientation and fast scan direction are indicated in the insets in the upper right corners).

While it may seem from Figure 1 that the direction of the stripes of adjacent grains is correlated, a closer analysis revealed that the twin domains in area 1 and 2 in Figure 1 (c) have an angle of $4.5^{\circ}$ with respect to each other. A complimentary measurement on a larger area of 40 $\mu \mathrm{m} \times 40 \mu \mathrm{m}$ further confirmed that there is no correlation of the pattern across grain boundaries 
(Figure 2). Figure 2 (a) shows the topography of the large scale scan. Highlighted by the black boxes in (a) are the areas that were magnified in Figure 2 (b) to image the PFM amplitude on adjacent perovskite grains. Here, it is apparent that the stripe direction on adjacent grains is not correlated.

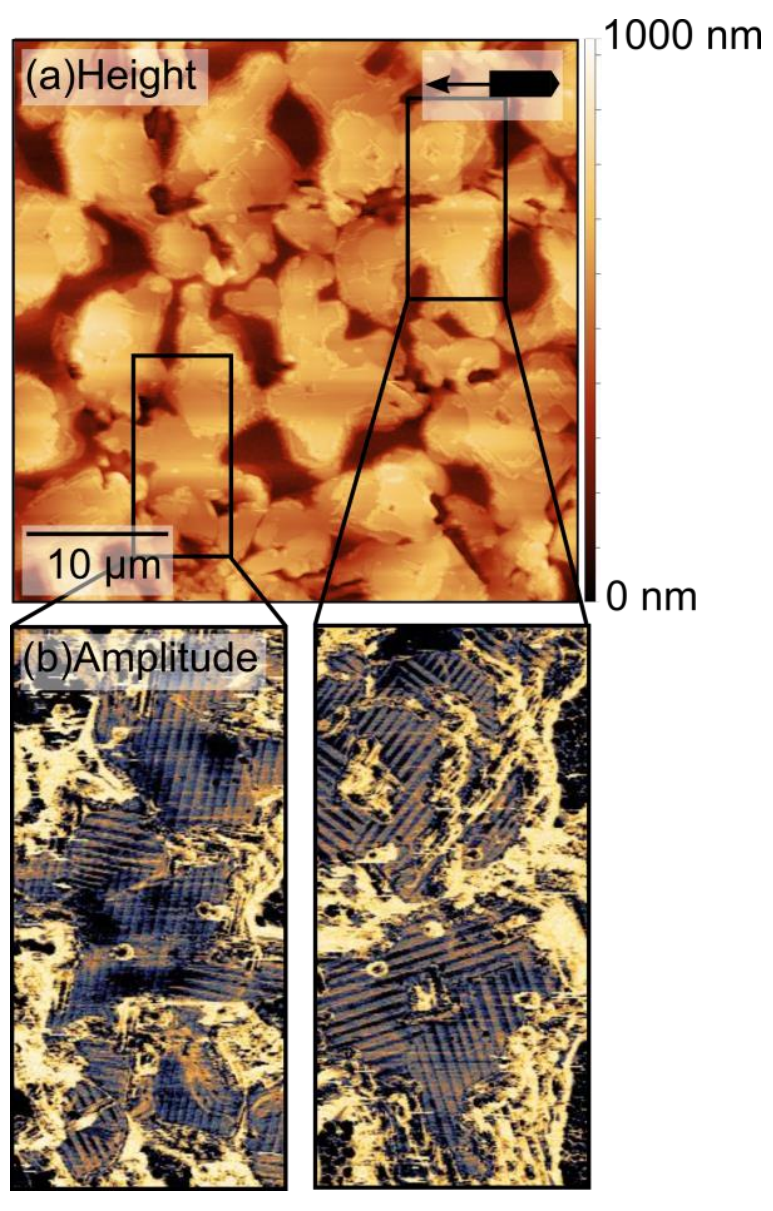

Figure 2. Vertical PFM measurement on $\mathrm{MAPbI}_{3}$ film (a) Topography, (b) PFM amplitude of magnified areas indicated by the blackes box in (a) $\left(V_{A C}=1.5 \mathrm{~V} ; f_{\text {Drive }}=290 \mathrm{kHz}\right.$, scan angle $=$ $0^{\circ}$, cantilever orientation and fast scan direction are indicated in the insets in the upper right corner).

To further characterize the texture of the polycrystalline $\mathrm{MAPbI}_{3}$ film we used x-ray diffraction (XRD) (Figure $3(\mathrm{a})$ ). The peak positions at $14.11^{\circ}, 19.95^{\circ}, 23.42^{\circ}, 24.42^{\circ}, 28.38^{\circ}$ and $31.76^{\circ}$ 
extracted from the radial averaged XRD pattern correspond to the (110), (200), (211), (202), (220) and (310) Bragg reflections of the tetragonal $\mathrm{MAPbI}_{3}$ structure, respectively (Figure 3 (b)). ${ }^{32,}{ }^{49-52}$ The weak reflection at $12.67^{\circ}$ indicates the presence of crystalline $\mathrm{PbI}_{2}$ in the sample. ${ }^{50,52-53}$ Likely, this is caused by partial degradation of $\mathrm{MAPbI}_{3}$ during the annealing at temperatures of $100{ }^{\circ} \mathrm{C} .{ }^{54}$ Consistent with previous studies, no reflections related to $\mathrm{MAPbCl}_{3}$ were observed. Furthermore, the absence of split peaks excludes a phase separation into iodide and chloride rich phases as origin of the domain pattern. ${ }^{55}$
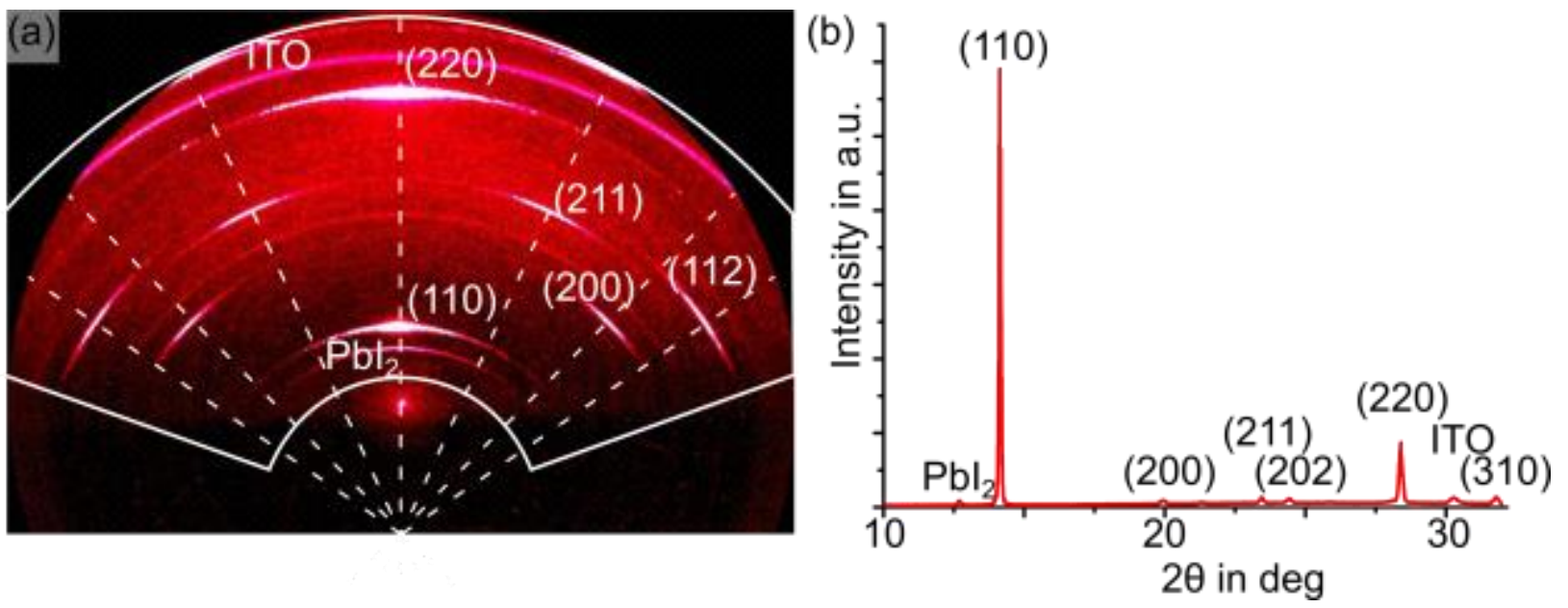

Figure 3. (a) $2 \mathrm{D}$ x-ray diffraction pattern of $\mathrm{MAPbI}_{3}$. Dashed lines indicate the azimuthal angle where maxima in the perovskite Bragg reflections were observed. (b) Radially integrated intensity in the sector indicated in (a) by solid white lines.

The pronounced radial intensity variations observed in the $2 \mathrm{D}$ data-sets indicate a strong preferential grain orientation within the polycrystalline perovskite film (Figure 3 (a)). For the (110) and the (220) reflections, intensity maxima were observed close to the specular condition. In contrast, for the (200) reflection two off-specular maxima at $\chi=45^{\circ}$ and $\chi=135^{\circ}$ were observed (dashed lines in Figure 3 (a) and Supporting Info Figure S3). This suggests that the 
(110) crystal plane of the perovskite grains is predominantly orientated parallel to the film surface. No preferred in-plane orientation of the grains was observed in the XRD measurements.

As the weak phase contrast in Figure 1(b) suggested, the observation of a vertical PFM signal could be caused by purely or partially in-plane oriented domains. In-plane components of the domain orientation can induce a vertical PFM signal via cantilever buckling (Figure 4(a)). Cantilever buckling can be distinguished from deflection of the cantilever by rotating the sample by $90^{\circ} .^{36}$ Signals from cantilever buckling are strongly dependent on the angle between cantilever and the domain orientation, whereas true out-of-plane sample deformations do not show such dependence. Upon rotating the sample by $90^{\circ}$ with respect to the cantilever, we indeed observed a contrast inversion in the vertical PFM amplitude and phase (Figure 4 (b-e)). This indicates that the orientation of the domains has an in-plane component and the vertical signal is at least partially caused by cantilever buckling.

(a)
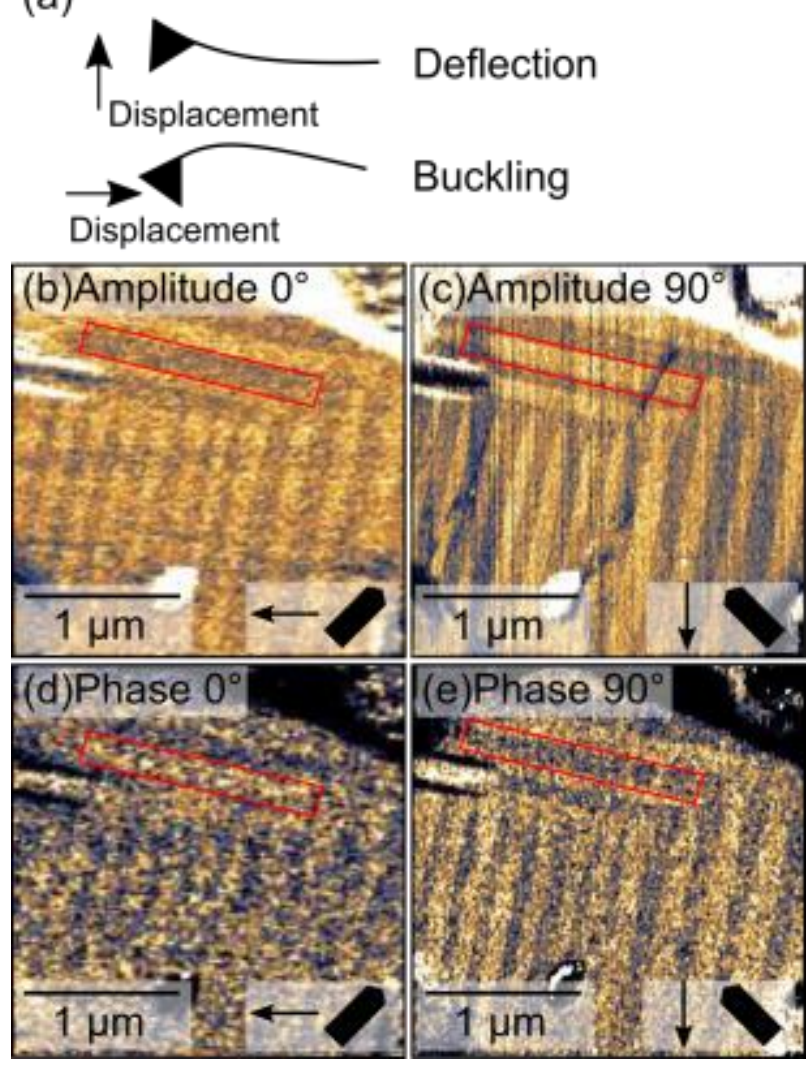
Figure 4. (a) Illustration of difference between deflection and cantilever buckling. (b) - (e) Vertical PFM measurement on $\mathrm{MAPbI}_{3}$ film $\left(V_{A C}=2.5 \mathrm{~V} ; f_{\text {Drive }}=300 \mathrm{kHz}\right.$, scan angle $=45^{\circ}$, cantilever orientation and fast scan direction are indicated in the insets in the lower right corners). (b) PFM amplitude at $0^{\circ}$ sample rotation and (c) at $90^{\circ}$ sample rotation, (d) PFM phase at $0^{\circ}$ sample rotation and (e) at $90^{\circ}$ sample rotation. The red box marks the same domain in (b) (e).

Considering the in-plane component of the domain orientation and the texture of the perovskite grains, there are three possible domain structures within the (110) crystal plane. The $a$-c-phase (Figure 5 (a)) consists of in-plane domains oriented along the $c$-axis of the unit cell that alternate with domains, in which the strain is oriented along the $a$-axis in a $45^{\circ}$ angle with respect to the surface. However, if only one of the domains is oriented out-of-plane ( $a$-domain) while the other domain is oriented in-plane (c-domain), the domain pattern will most likely be visible in the topography of the sample. The differences in the lattice parameters $a$ and $c$ cause a roof-like structure in the topography. The latter is the case for the ferroelectric and -elastic $\mathrm{PbTiO}_{3}$ and $\mathrm{BaTiO}_{3}$ domains oriented along the $c$-axis (out-of-plane) and the $a$-axis (in-plane) of the tetragonal unit cell. ${ }^{48,56}$ Since the striped pattern in the $\mathrm{MAPbI}_{3}$ grains could not be observed in the topography, we conclude that both twinning domains are either oriented in the same non- $90^{\circ}$ angle out-of-plane or purely in-plane. 

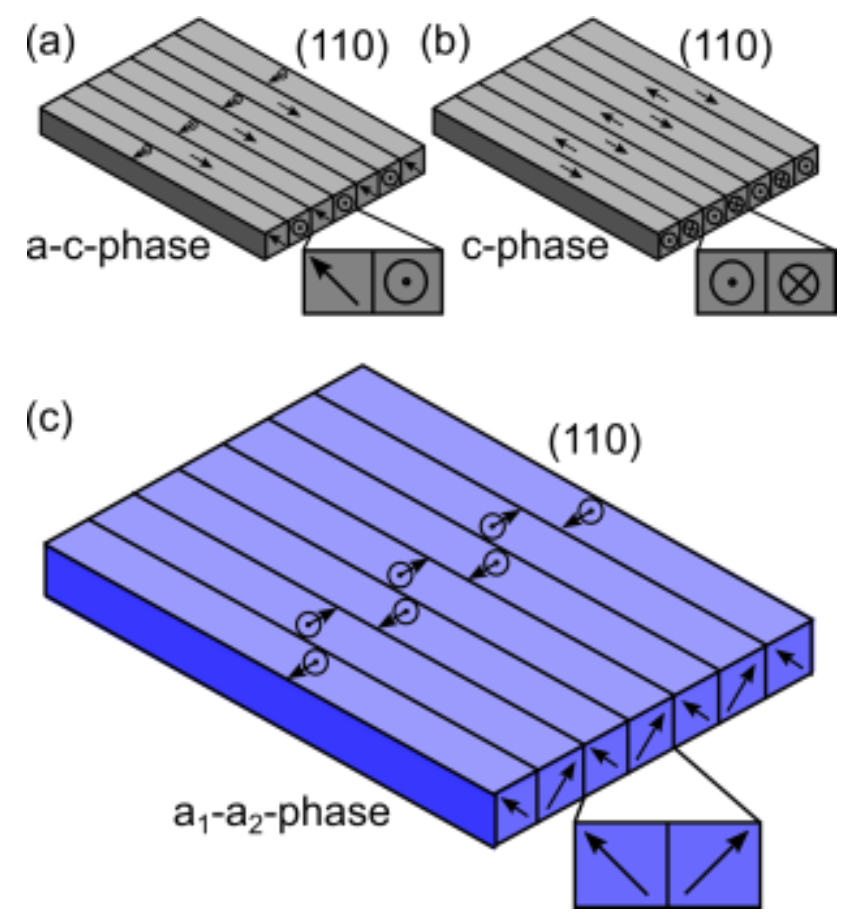

Figure 5. Possible orientations of the strain along the crystal axes (indicated by the arrows) of the twin domains within the (110) crystal plane of $\mathrm{MAPbI}_{3}$ : (a) $a$-c-phase with alternating out-of plane domains along the $a$-axis and in-plane domains along the $c$-axis, (b) purely in-plane $c$ phase with antiparallel domains, (c) proposed $a_{1}$ - $a_{2}$-phase in a $45^{\circ}$ angle out-of-plane and $90^{\circ}$ with respect to each other.

A purely in-plane structure consists of neighboring domains in an antiparallel orientation along the $c$-axis (c-phase, Figure 5 (b)). Assuming such a domain structure and that the vertical PFM signal is only caused by cantilever buckling, we would expect the PFM amplitudes on all the stripes that are oriented parallel to the cantilever to be of the same value. However, in Figure 1 (c) the PFM amplitude shows the same alternating contrast on different stripe orientations and even for stripes parallel to the cantilever (e.g. in magnified area 1).

Based on the results presented so far we propose a domain structure, in which the strain of adjacent twin domains is oriented in a $45^{\circ}$ angle to the surface and a $90^{\circ}$ angle with respect to 
each other ( $a_{1}$ - $a_{2}$-phase, Figure 5 (c)). The vertical PFM signal would be caused by a combination of cantilever deflection and buckling. Thereby, the observed inversion in the vertical PFM contrast upon sample rotation can be explained. As the strain in the $a_{1}$ - $a_{2}$-phase has equal out-of-plane components for adjacent domains the structure would not be visible in the topography.

To further support the suggested $a_{1}-a_{2}$ domain structure within the $\mathrm{MAPbI}_{3}$ grains we performed lateral PFM measurements on the film. The perovskite film showed a lateral piezoresponse (Figure 6 (a) and (b)), which resembled the periodic pattern observed in the vertical PFM measurements (Figure 1). The presence of a lateral PFM signal confirms that the orientation of the domain structures has an in-plane component. By measuring at $0^{\circ}$ and $90^{\circ}$ sample rotation it is possible to determine the domain orientation from the change of the phase contrast (Figure 6 (a)). ${ }^{36}$ Upon rotating the sample by $90^{\circ}$ from Figure 6 (a) to (b), the PFM phase contrast was inverted, while the contrast in the PFM amplitude remained largely unchanged (insets in Figure 6 (a) and (b)). In the area highlighted by the red oval this inversion is very distinct. 

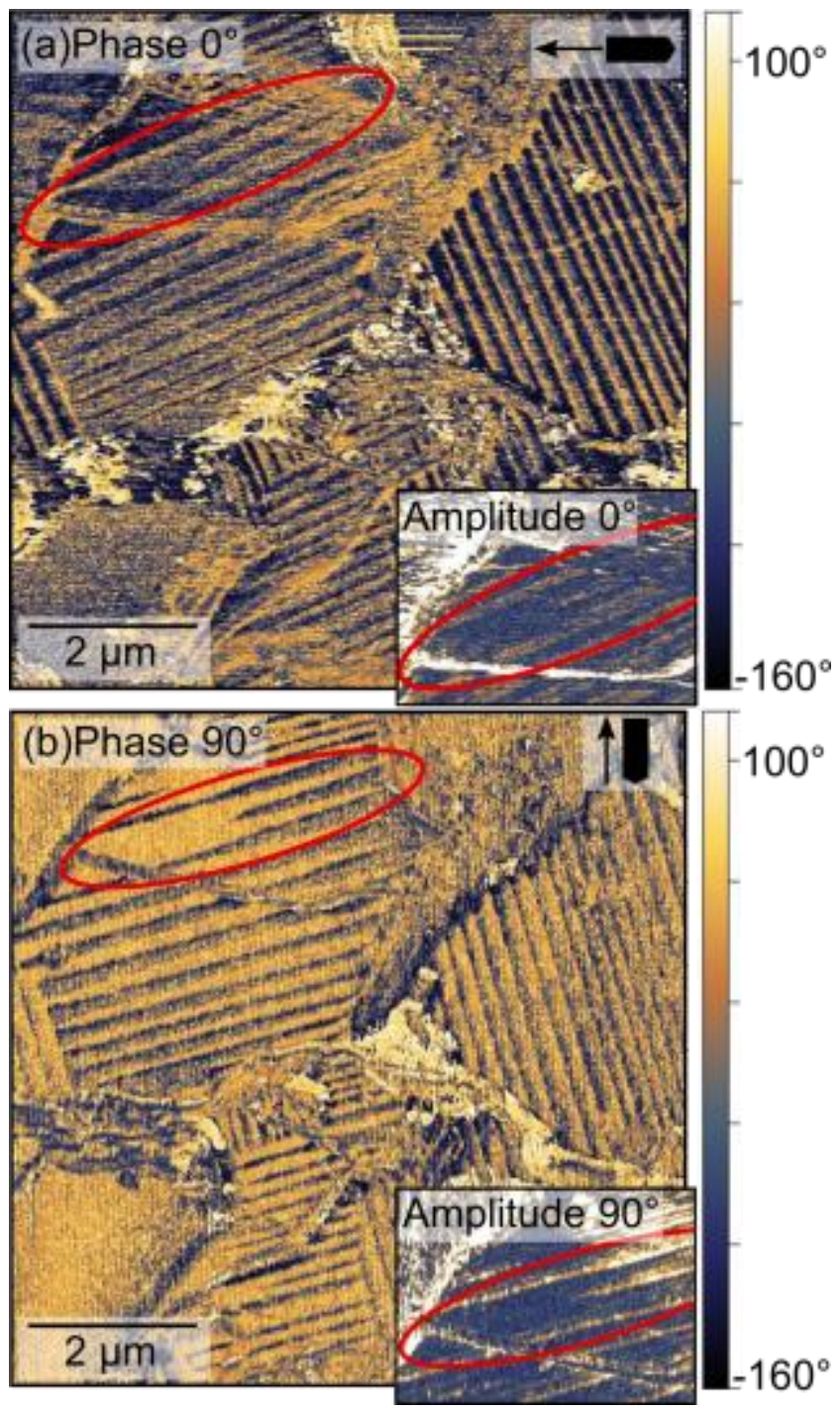

Figure 6. Lateral PFM on $\mathrm{MAPbI}_{3}$ film (a) PFM phase at $0^{\circ}$ and (b) at $90^{\circ}$ sample rotation. The insets in the lower right corner show the PFM amplitude both with the same data scale. The red oval marks the same domains $\left(V_{A C}=2.5 \mathrm{~V} ; f_{\text {Drive }}=600 \mathrm{kHz}\right.$, scan angle $=0^{\circ}$, cantilever orientation and scan direction are indicated in the insets in the upper right corners).

Both twin domains in the $a_{1}-a_{2}$-phase (Figure $5(\mathrm{c})$ ) have the same angle with respect to the cantilever. Therefore, the contrast inversion in the PFM phase and the unchanged PFM amplitude upon sample rotation are in agreement with this domain structure assignment (Figure $5(\mathrm{c}))$. 
Subsequently, we performed ferroelectric switching experiments to examine whether the ferroelastic stripes contribute to a possible ferroelectricity of the perovskite. During an AFM scan in contact mode we applied DC voltages between $+4 \mathrm{~V}$ and $-4 \mathrm{~V}$ to the tip with scan rates between $0.3 \mathrm{~Hz}$ to $1 \mathrm{~Hz}$. We did not use higher voltages to avoid damage to the sample. In case of ferroelectric switching, the contrast of the phase of the piezoresponse should be inverted in a subsequent PFM scan. However, the contrast of the PFM signals and the arrangement of the stripes remained unchanged after applying a DC bias in agreement with Xiao et al. ${ }^{19}$ We locally measured ferroelectric hysteresis loops, which did not show a switching event (Supporting Information Figure S4).

The absence of polarization switching in the above experiments, however, does not generally exclude ferroelectricity. Wei et al. observed switching in the orientation of ferroelectric domains on the timescales of several seconds. ${ }^{17}$ We performed the DC scans with velocities between 3 $12 \mu \mathrm{m} / \mathrm{s}$, which might be too fast to switch the domain orientation. In context of the $I-V$ hysteresis, several studies have reported on slow processes within the perovskite layer and connected them to migrating ions or trapped charges. ${ }^{5-6,13,19-22}$ The resulting internal electric field could also screen the applied DC voltage and interfere with the ferroelectric switching. As the perovskite is electrically conductive, it is also possible that the conductivity induces a breakdown of the tip voltage which is then insufficient to switch the orientation of the polarization within the domains. Finally, if the ferroelectric polarization has in-plane components, these domains cannot easily be switched via AFM methods. The field that is applied to the film by an AFM tip is mainly perpendicular to the surface, which makes the switching of in-plane domains unlikely, but not impossible. ${ }^{48}$ 

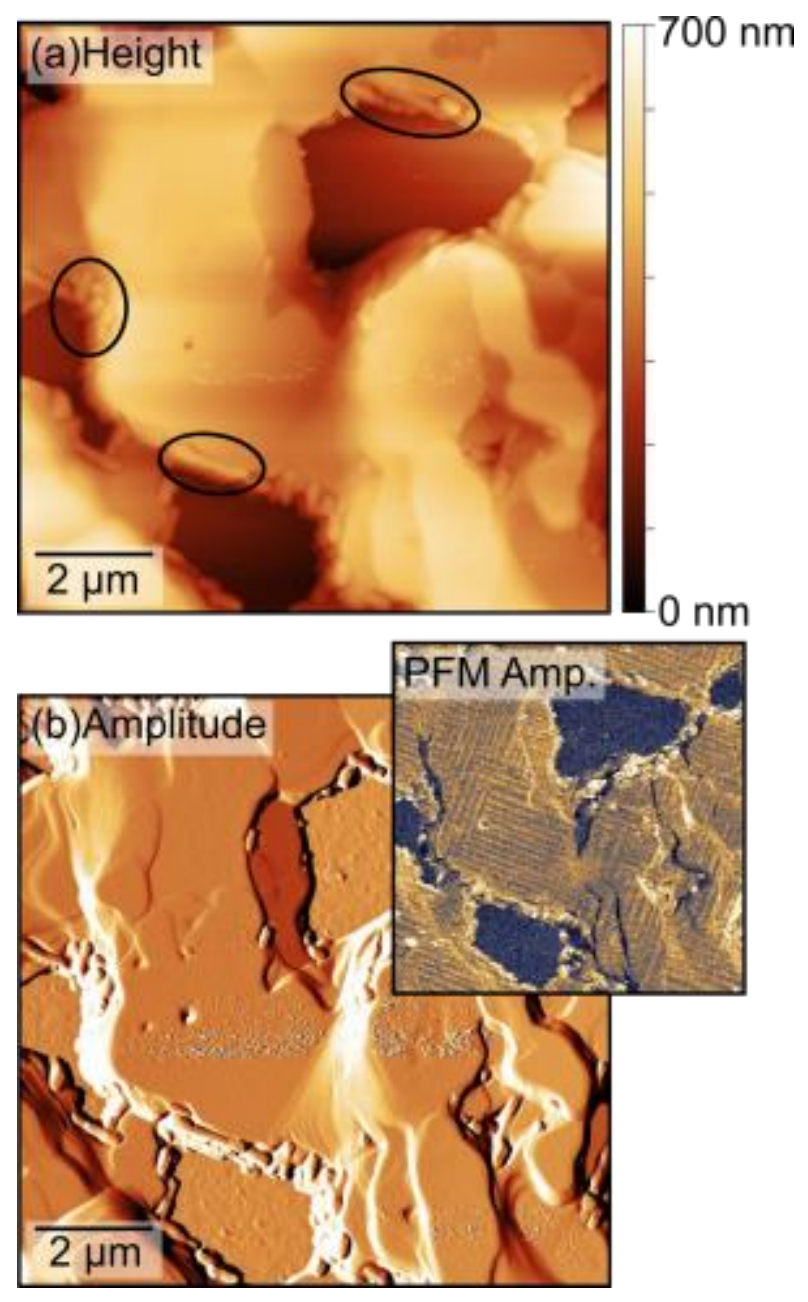

Figure 7. Tapping mode measurement on $\mathrm{MAPbI}_{3}$ film. (a) Topography and (b) amplitude error signal. The PFM amplitude of the same area is shown in the upper right corner of (b) for comparison.

To exclude topographic crosstalk as the origin of the periodic pattern in the PFM signals, we additionally probed the sample topography with the less invasive tapping mode AFM (Figure 7). Neither the height (Figure 7 (a)) nor the amplitude error signal (Figure 7 (b)) correlated to the striped pattern observed in the PFM amplitude signal of the same area, as shown in the upper right corner of Figure 7 (b). The striped pattern appeared in the PFM signals, only. However, we observed terraces and steps on the grains indicating a layered crystallite growth. 
The perovskite layer was up to $1 \mu \mathrm{m}$ thick but did not completely cover the substrate. Holes reaching down to the PEDOT:PSS, corresponding to the dark areas in the height channel (Figure 7 (a)), showed no PFM response (Figure 7 (b)). We can therefore exclude that the observed piezoresponse was caused by the substrate. At the edges of the grains we observed small rods, highlighted by the black ovals in Figure 7 (a), which are between $150 \mathrm{~nm}$ and $700 \mathrm{~nm}$ long and $100 \mathrm{~nm}$ to $200 \mathrm{~nm}$ wide. We assigned these rods to the perovskite degradation product $\mathrm{PbI}_{2}$. This assignment is in agreement with the XRD results discussed above (Figure 3) and UV-vis spectroscopy results (Supporting Information Figure S5).

\section{CONCLUSION}

We examined the electromechanical response of $\mu \mathrm{m}$-sized $\mathrm{MAPbI}_{3}$ grains by PFM. Distinct periodic domains were observed with distances between $100 \mathrm{~nm}$ and $350 \mathrm{~nm}$. These striped domains in the piezoresponse were oriented either parallel or perpendicular with respect to each other - a characteristic fingerprint of ferroelasticity. ${ }^{34}$ Previous PFM studies on polycrystalline perovskite films did not observe such a domain pattern. These studies used different preparation routes, such as the successive spin coating/annealing routine ${ }^{38}$ or a two-step thermal/solvent annealing routine ${ }^{19}$ and yielded dense films of $\mathrm{MAPbI}_{3}$ grains with sizes up to $1 \mu \mathrm{m}$. None of the studies obtained grains with a similar terrace structure as the samples presented in this study. We therefore propose that $\mathrm{MAPbI}_{3}$ is ferroelastic and that the periodic twin domains observed form to minimize internal strain caused by the morphology resulting from the preparation route chosen. Stress from the cubic-tetragonal phase transition following sample annealing could induce the internal strain. However, independent from the observation of the domain pattern, ferroelasticity is a property that would be present in $\mathrm{MAPbI}_{3}$, even when prepared otherwise. To 
finally prove the ferroelasticity in perovskite, further measurements such as mechanic hysteresis experiments will be necessary.

At ferroelastic domain walls, localized properties such as superconductivity or ferroelectricity can occur that are not present in the bulk material, since the walls can act as sources for defects. ${ }^{57}$ Conducting ferroelastic domain walls that can be caused by head-to-head and tail-to-tail orientation could be an alternative explanation of the increased charge carrier diffusion lengths in large $\mathrm{MAPbI}_{3}$ grains, yet also contribute to the $I-V$ hysteresis by trapping free charge carriers in defects. To further investigate the properties of the ferroelastic domain walls in $\mathrm{MAPbI}_{3}$, local conductivity measurements, e.g. via conductive AFM with and without illumination would be required.

The XRD results revealed that the (110) crystal plane is oriented parallel to the sample surface. By performing vertical and lateral PFM experiments at $0^{\circ}$ and $90^{\circ}$ sample rotation with we were able to identify the $a_{1}-a_{2}$-phase as the preferred orientation of the ferroelastic domains with respect to the sample surface. Finally, ferroelectric switching experiments suggested the absence of an out-of-plane switchable polarization in the perovskite films.

\section{Author Information}

\section{Corresponding Author}

* S. A. L. Weber; E-mail: webers@mpip-mainz.mpg.de

\section{Notes}

The authors declare no competing financial interest.

\section{Author Contributions}


The manuscript was written through contributions of all authors. All authors have given approval to the final version of the manuscript.

Acknowledgement

The authors thank Doru C. Lupascu and Florian Johann (Asylum Research) for vivid discussions. R.B. and V.W.B. thank the IRTG 1404 for funding, F.L. thanks the Max Planck Society for funding the Max Planck Research Group, D.L. thanks China Scholarship Council (CSC) for funding.

Supporting Information Available

PFM amplitude in dependence of $V_{A C}$ voltage, $\mathrm{PFM}$ measurement of $\mathrm{MAPbI}_{3}$ on ITO, intensity distributions of the (110) and the (200) Bragg reflections, ferroelectric switching experiment, UV-vis absorption spectra of $\mathrm{MAPbI}_{3}$. This information is available free of charge via the Internet at http://pubs.acs.org

References

1. Kojima, A.; Teshima, K.; Shirai, Y.; Miyasaka, T., Organometal Halide Perovskites as Visible-Light Sensitizers for Photovoltaic Cells. J. Am. Chem. Soc. 2009, 131, 6050-6051.

2. Kim, H.-S., et al., Lead Iodide Perovskite Sensitized All-Solid-State Submicron Thin Film Mesoscopic Solar Cell with Efficiency Exceeding 9\%. Sci. Rep. 2012, 2.

3. Lee, M. M.; Teuscher, J.; Miyasaka, T.; Murakami, T. N.; Snaith, H. J., Efficient Hybrid Solar Cells Based on Meso-Superstructured Organometal Halide Perovskites. Science 2012, 338, 643-647.

4. Yang, W. S.; Noh, J. H.; Jeon, N. J.; Kim, Y. C.; Ryu, S.; Seo, J.; Seok, S. I., HighPerformance Photovoltaic Perovskite Layers Fabricated through Intramolecular Exchange. Science 2015.

5. Gratzel, M., The Light and Shade of Perovskite Solar Cells. Nat. Mater. 2014, 13, 838842.

6. $\quad$ McGehee, M. D., Perovskite Solar Cells: Continuing to Soar. Nat. Mater. 2014, 13, 845846. 
7. Snaith, H. J., Perovskites: The Emergence of a New Era for Low-Cost, High-Efficiency Solar Cells. J. Phys. Chem. Lett. 2013, 4, 3623-3630.

8. Kazim, S.; Nazeeruddin, M. K.; Grätzel, M.; Ahmad, S., Perovskite as Light Harvester: A Game Changer in Photovoltaics. Angew. Chem. Int. Ed. 2014, 53, 2812-2824.

9. Stranks, S. D.; Eperon, G. E.; Grancini, G.; Menelaou, C.; Alcocer, M. J. P.; Leijtens, T.; Herz, L. M.; Petrozza, A.; Snaith, H. J., Electron-Hole Diffusion Lengths Exceeding 1 Micrometer in an Organometal Trihalide Perovskite Absorber. Science 2013, 342, 341-344. 10. Wehrenfennig, C.; Eperon, G. E.; Johnston, M. B.; Snaith, H. J.; Herz, L. M., High Charge Carrier Mobilities and Lifetimes in Organolead Trihalide Perovskites. Adv. Mater. 2014, 26, 1584-1589.

11. Nazeeruddin, M. K.; Snaith, H., Methylammonium Lead Triiodide Perovskite Solar Cells: A New Paradigm in Photovoltaics. MRS Bulletin 2015, 40, 641-645.

12. Frost, J. M.; Butler, K. T.; Brivio, F.; Hendon, C. H.; van Schilfgaarde, M.; Walsh, A., Atomistic Origins of High-Performance in Hybrid Halide Perovskite Solar Cells. Nano Lett. 2014, 14, 2584-2590.

13. Snaith, H. J.; Abate, A.; Ball, J. M.; Eperon, G. E.; Leijtens, T.; Noel, N. K.; Stranks, S. D.; Wang, J. T.-W.; Wojciechowski, K.; Zhang, W., Anomalous Hysteresis in Perovskite Solar Cells. J. Phys. Chem. Lett. 2014, 5, 1511-1515.

14. Frost, J. M.; Butler, K. T.; Walsh, A., Molecular Ferroelectric Contributions to Anomalous Hysteresis in Hybrid Perovskite Solar Cells. APL Mat. 2014, 2, 081506 (10 pp.)081506 (10 pp.).

15. Chen, H.-W.; Sakai, N.; Ikegami, M.; Miyasaka, T., Emergence of Hysteresis and Transient Ferroelectric Response in Organo-Lead Halide Perovskite Solar Cells. J. Phys. Chem. Lett. 2015, 6, 164-169.

16. Chen, B.; Zheng, X.; Yang, M.; Zhou, Y.; Kundu, S.; Shi, J.; Zhu, K.; Priya, S., Interface Band Structure Engineering by Ferroelectric Polarization in Perovskite Solar Cells. Nano Energy 2015, 13, 582-591.

17. Wei, J.; Zhao, Y.; Li, H.; Li, G.; Pan, J.; Xu, D.; Zhao, Q.; Yu, D., Hysteresis Analysis Based on the Ferroelectric Effect in Hybrid Perovskite Solar Cells. J. Phys. Chem. Lett. 2014, 5, 3937-3945.

18. O’Regan, B. C.; Barnes, P. R. F.; Li, X.; Law, C.; Palomares, E.; Marin-Beloqui, J. M., Optoelectronic Studies of Methylammonium Lead Iodide Perovskite Solar Cells with Mesoporous Tio2: Separation of Electronic and Chemical Charge Storage, Understanding Two Recombination Lifetimes, and the Evolution of Band Offsets During J-V Hysteresis. J. Am. Chem. Soc. 2015, 137, 5087-5099.

19. Xiao, Z.; Yuan, Y.; Shao, Y.; Wang, Q.; Dong, Q.; Bi, C.; Sharma, P.; Gruverman, A.; Huang, J., Giant Switchable Photovoltaic Effect in Organometal Trihalide Perovskite Devices. Nat. Mater. 2015, 14, 193-198.

20. Beilsten-Edmands, J.; Eperon, G. E.; Johnson, R. D.; Snaith, H. J.; Radaelli, P. G., NonFerroelectric Nature of the Conductance Hysteresis in Ch3nh3pbi3 Perovskite-Based Photovoltaic Devices. Appl. Phys. Lett. 2015, 106, 173502.

21. Zhang, Y., et al., Charge Selective Contacts, Mobile Ions and Anomalous Hysteresis in Organic-Inorganic Perovskite Solar Cells. Mater. Horiz. 2015, 2, 315-322.

22. Bergmann, V. W.; Weber, S. A. L.; Javier Ramos, F.; Nazeeruddin, M. K.; Grätzel, M.; Li, D.; Domanski, A. L.; Lieberwirth, I.; Ahmad, S.; Berger, R., Real-Space Observation of 
Unbalanced Charge Distribution inside a Perovskite-Sensitized Solar Cell. Nat. Commun. 2014, 5 .

23. Tress, W.; Marinova, N.; Moehl, T.; Zakeeruddin, S. M.; Nazeeruddin, M. K.; Gratzel, M., Understanding the Rate-Dependent J-V Hysteresis, Slow Time Component, and Aging in Ch3nh3pbi3 Perovskite Solar Cells: The Role of a Compensated Electric Field. Energy \& Environmental Science 2015, 8, 995-1004.

24. Unger, E. L.; Hoke, E. T.; Bailie, C. D.; Nguyen, W. H.; Bowring, A. R.; Heumuller, T.; Christoforo, M. G.; McGehee, M. D., Hysteresis and Transient Behavior in Current-Voltage Measurements of Hybrid-Perovskite Absorber Solar Cells. Energy \& Environmental Science 2014, 7, 3690-3698.

25. $\quad$ van Reenen, S.; Kemerink, M.; Snaith, H. J., Modeling Anomalous Hysteresis in Perovskite Solar Cells. The Journal of Physical Chemistry Letters 2015, 6, 3808-3814.

26. Stoumpos, C. C.; Malliakas, C. D.; Kanatzidis, M. G., Semiconducting Tin and Lead Iodide Perovskites with Organic Cations: Phase Transitions, High Mobilities, and near-Infrared Photoluminescent Properties. Inorg. Chem. 2013, 52, 9019-9038.

27. Dang, Y.; Liu, Y.; Sun, Y.; Yuan, D.; Liu, X.; Lu, W.; Liu, G.; Xia, H.; Tao, X., Bulk Crystal Growth of Hybrid Perovskite Material Ch3nh3pbi3. CrystEngComm 2015, 17, 665-670. 28. Weller, M. T.; Weber, O. J.; Henry, P. F.; Di Pumpo, A. M.; Hansen, T. C., Complete Structure and Cation Orientation in the Perovskite Photovoltaic Methylammonium Lead Iodide between 100 and 352 K. Chem. Commun. 2015, 51, 4180-4183.

29. Bretschneider, S. A.; Weickert, J.; Dorman, J. A.; Schmidt-Mende, L., Research Update: Physical and Electrical Characteristics of Lead Halide Perovskites for Solar Cell Applications. APL Mat. 2014, 2, 040701.

30. Poglitsch, A.; Weber, D., Dynamic Disorder in Methylammoniumtrihalogenoplumbates (Ii) Observed by Millimeter-Wave Spectroscopy. J. Chem. Phys. 1987, 87, 6373-6378.

31. Kawamura, Y.; Mashiyama, H.; Hasebe, K., Structural Study on Cubic-Tetragonal Transition of Ch3nh3pbi3. J. Phys. Soc. Jpn. 2002, 71, 1694-1697.

32. Baikie, T.; Fang, Y. N.; Kadro, J. M.; Schreyer, M.; Wei, F. X.; Mhaisalkar, S. G.; Graetzel, M.; White, T. J., Synthesis and Crystal Chemistry of the Hybrid Perovskite (Ch3nh3) Pbi3 for Solid-State Sensitised Solar Cell Applications. J. Mater. Chem. A 2013, 1, 5628-5641. 33. Tagantsev, A. K.; Cross, L. E.; Fousek, J., Domains in Ferroic Crystals and Thin Films; Springer New York, 2010.

34. Salje, E. K. H., Phase Transitions in Ferroelastic and Co-Elastic Crystals; Cambridge University Press: Cambridge, NY, USA, 1990.

35. Berger, R.; Domanski, A. L.; Weber, S. A. L., Electrical Characterization of Organic Solar Cell Materials Based on Scanning Force Microscopy. Eur. Polym. J. 2013, 49, 1907-1915. 36. Soergel, E., Piezoresponse Force Microscopy (Pfm). J. Phys. D: Appl. Phys. 2011, 44, 464003.

37. Kalinin, S. V.; Rodriguez, B. J.; Kholkin, A. L., Piezoresponse Force Microscopy and Spectroscopy. In Encyclopedia of Nanotechnology, Bhushan, B., Ed. Springer Netherlands: 2012; pp 2117-2125.

38. Kutes, Y.; Ye, L.; Zhou, Y.; Pang, S.; Huey, B. D.; Padture, N. P., Direct Observation of Ferroelectric Domains in Solution-Processed Ch3nh3pbi3 Perovskite Thin Films. J. Phys. Chem. Lett. 2014, 3335-3339.

39. Chen, B.; Shi, J.; Zheng, X.; Zhou, Y.; Zhu, K.; Priya, S., Ferroelectric Solar Cells Based on Inorganic-Organic Hybrid Perovskites. J. Mater. Chem. A 2015, 3, 7699-7705. 
40. Kim, H.-S.; Kim, S. K.; Kim, B. J.; Shin, K.-S.; Gupta, M. K.; Jung, H. S.; Kim, S.-W.; Park, N.-G., Ferroelectric Polarization in Ch3nh3pbi3 Perovskite. J. Phys. Chem. Lett. 2015, 1729-1735.

41. Zhao, P.; Xu, J.; Ma, C.; Ren, W.; Wang, L.; Bian, L.; Chang, A., Spontaneous Polarization Behaviors in Hybrid Halide Perovskite Film. Scr. Mater. 2015, 102, 51-54.

42. Coll, M.; Gomez, A.; Mas-Marza, E.; Almora, O.; Garcia-Belmonte, G.; Campoy-Quiles, M.; Bisquert, J., Polarization Switching and Light-Enhanced Piezoelectricity in Lead Halide Perovskites. J. Phys. Chem. Lett. 2015, 6, 1408-1413.

43. Fan, Z.; Xiao, J.; Sun, K.; Chen, L.; Hu, Y.; Ouyang, J.; Ong, K. P.; Zeng, K.; Wang, J., Ferroelectricity of Ch3nh3pbi3 Perovskite. J. Phys. Chem. Lett. 2015, 6, 1155-1161.

44. Xiao, Z.; Dong, Q.; Bi, C.; Shao, Y.; Yuan, Y.; Huang, J., Solvent Annealing of Perovskite-Induced Crystal Growth for Photovoltaic-Device Efficiency Enhancement. Adv Mater 2014, 26, 6503-9.

45. Kholkin, A. L.; Pertsev, N. A.; Goltsev, A. V., Piezoelectricity and Crystal Symmetry. In Piezoelectric and Acoustic Materials for Transducer Applications., Safari, A.; Akdogan, E. K., Eds. Springer US: 2008; pp 17-38.

46. Cao, W.; Randall, C. A., Grain Size and Domain Size Relations in Bulk Ceramic Ferroelectric Materials. J. Phys. Chem. Solids 1996, 57, 1499-1505.

47. Ivry, Y.; Scott, J. F.; Salje, E. K. H.; Durkan, C., Nucleation, Growth, and Control of Ferroelectric-Ferroelastic Domains in Thin Polycrystalline Films. Phys. Rev. B 2012, 86, 205428.

48. Matzen, S.; Nesterov, O.; Rispens, G.; Heuver, J. A.; Biegalski, M.; Christen, H. M.; Noheda, B., Super Switching and Control of in-Plane Ferroelectric Nanodomains in Strained Thin Films. Nat. Commun. 2014, 5.

49. Song, Z.; Watthage, S. C.; Phillips, A. B.; Tompkins, B. L.; Ellingson, R. J.; Heben, M. J., Impact of Processing Temperature and Composition on the Formation of Methylammonium Lead Iodide Perovskites. Chem. Mater. 2015.

50. Christians, J. A.; Miranda Herrera, P. A.; Kamat, P. V., Transformation of the Excited State and Photovoltaic Efficiency of Ch3nh3pbi3 Perovskite Upon Controlled Exposure to Humidified Air. J. Am. Chem. Soc. 2015, 137, 1530-1538.

51. Park, N.-G., Perovskite Solar Cells: An Emerging Photovoltaic Technology. Mater. Today 2015, 18, 65-72.

52. Zhao, Y.; Zhu, K., Charge Transport and Recombination in Perovskite (Ch3nh3)Pbi3 Sensitized Tio2 Solar Cells. J. Phys. Chem. Lett. 2013, 4, 2880-2884.

53. Lee, Y. H.; Luo, J.; Humphry-Baker, R.; Gao, P.; Grätzel, M.; Nazeeruddin, M. K., Unraveling the Reasons for Efficiency Loss in Perovskite Solar Cells. Adv. Funct. Mater. 2015, 3925-3933.

54. Supasai, T.; Rujisamphan, N.; Ullrich, K.; Chemseddine, A.; Dittrich, T., Formation of a Passivating Ch3nh3pbi3/Pbi2 Interface During Moderate Heating of Ch3nh3pbi3 Layers. Appl. Phys. Lett. 2013, 103, 183906.

55. Yu, H.; Wang, F.; Xie, F.; Li, W.; Chen, J.; Zhao, N., The Role of Chlorine in the Formation Process of "Ch3nh3pbi3-Xclx" Perovskite. Adv. Funct. Mater. 2014, 24, 7102-7108. 56. Rubio-Marcos, F.; Del Campo, A.; Marchet, P.; Fernández, J. F., Ferroelectric Domain Wall Motion Induced by Polarized Light. Nat. Commun. 2015, 6.

57. Salje, E. K. H., Ferroelastic Materials. Annu. Rev. Mater. Res. 2012, 42, 265-283. 


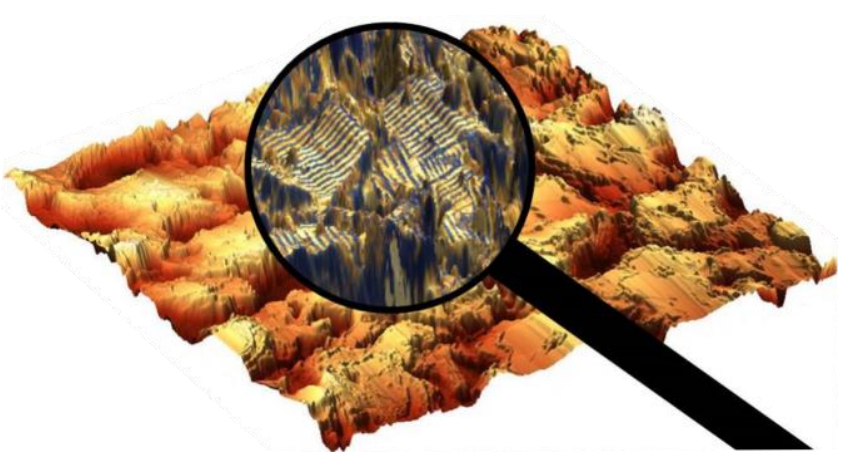

Table of content graphic 


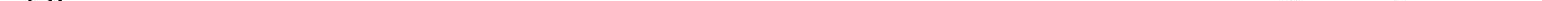




\section{(a)Hethghlournal of Physical asmpisoryf 33}

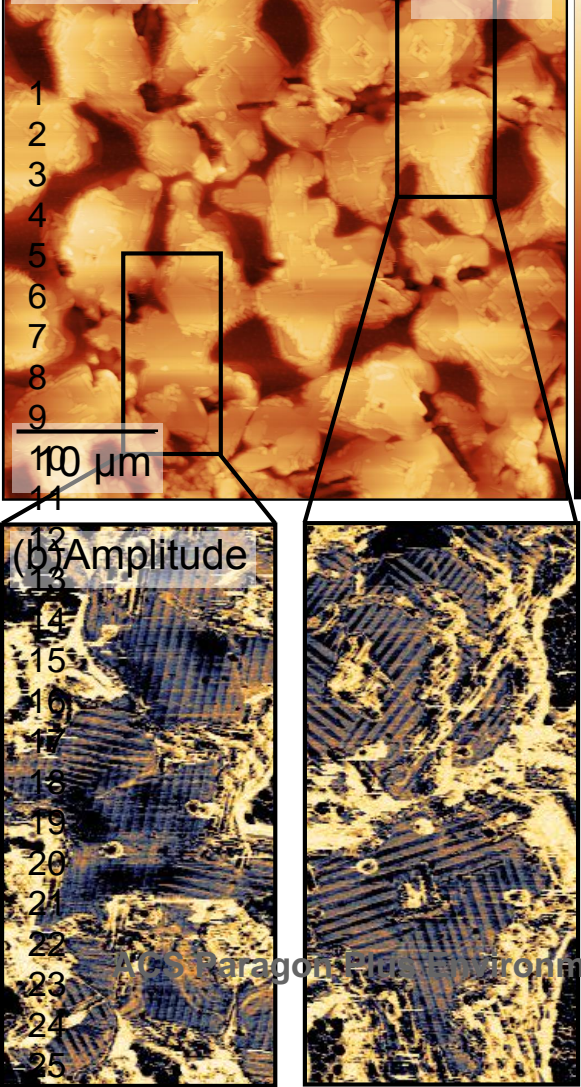




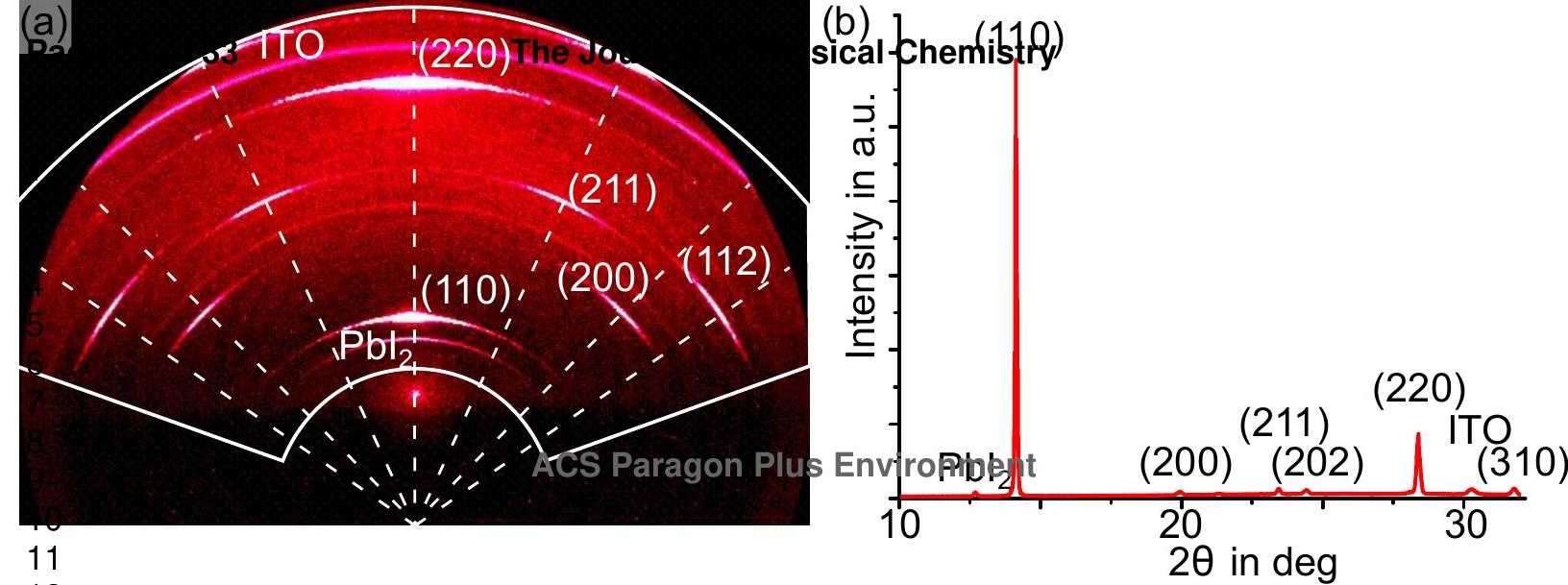


(a)

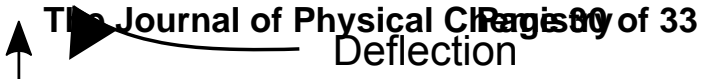
Displacement

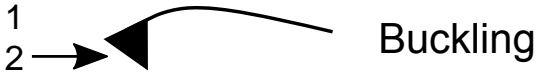

3 Displacement
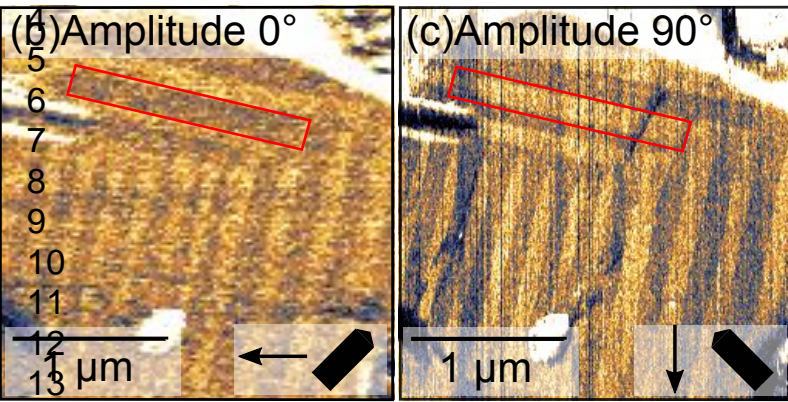

\section{(d)Phase $0^{\circ}$

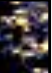

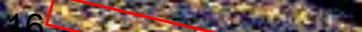

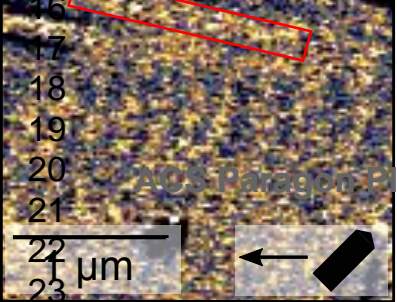
(e)Phase 90 40

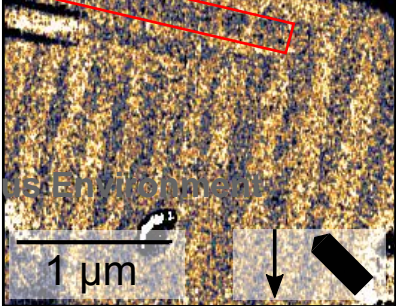


(a)

(110) (b)

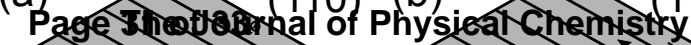

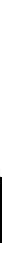

5

(c)

8

9

ire

11
12
13

14

15

16

17

ACS Paragol-
$a_{1}-a_{2}-$ phăse

18

c-phase
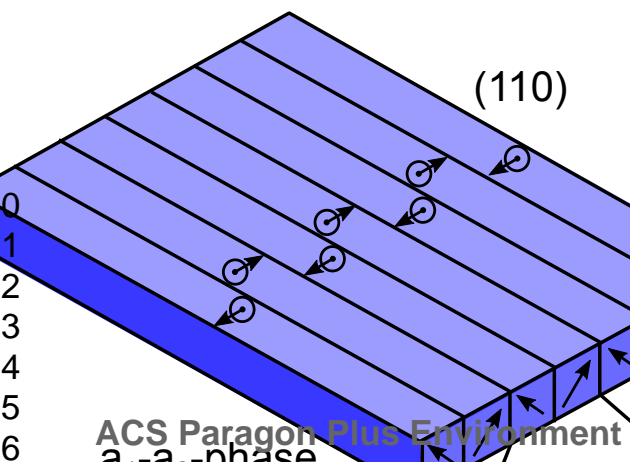

(c)
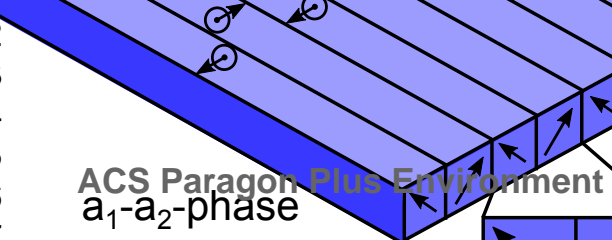

$\mathrm{a}_{1}-\mathrm{a}_{2}$-phase

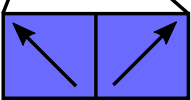




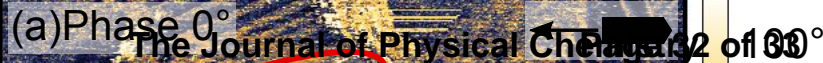

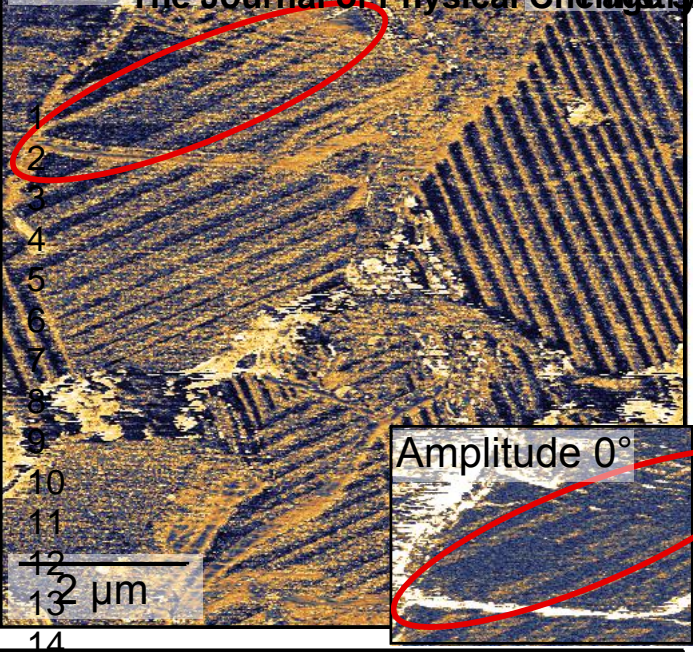

\section{(błPhase $90^{\circ}=$

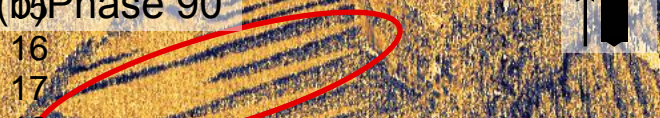

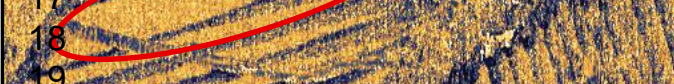

\section{$\frac{3}{2}$}

22

23

$24 \pi+2$.

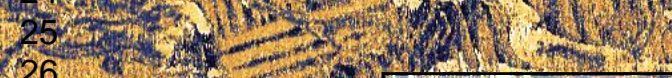

26
27
28
29
$\frac{29}{30} \mu \mathrm{m}=-2$


